\title{
Temporal changes in monocytic and neutrophilic trem- 1 and trem- 2 surface receptors in blood and bronchoalveolar lavage fluid in the development and resolution of ventilator-associated pneumonia (VAP)
}

\author{
V Grover ${ }^{1,2,3^{*}}$, P Kelleher ${ }^{4,5}, \mathrm{~S}$ Sing $\mathrm{h}^{2,3,6}$ \\ From ESICM LIVES 2015 \\ Berlin, Germany. 3-7 October 2015
}

\section{Introduction}

TREM-1 (Triggering Receptor Expressed on Myeloid Cells) amplifies Toll-like receptor (TLR) responses and is a putative biomarker to diagnose VAP. It exists on the surface of monocytes/macrophages (mTREM-1) and neutrophils (nTREM-1) as well as a soluble receptor (sTREM-1). Standalone levels of mTREM-1 in bronchoalveolar lavage fluid (BALF) and its BALF/blood ratio are elevated in VAP (1). TREM-2 (a negative TLR regulator) may also have a role in pneumonia (2), but there is a paucity of data in humans.

\section{Objectives}

To measure temporal changes in monocytic/macrophage and neutrophilic TREM-1 and TREM-2 surface receptor levels in blood and BALF during VAP development and resolution.

\section{Methods}

Serial receptor levels were assessed in 12 patients. 5 had levels measured prior to development of VAP, 2 with clinical worsening of VAP, 6 with VAP resolution and in one patient changes were tracked in all three stages. Patients were recruited in a teaching hospital ICU (mixed medical, surgical and burns patients). Alternate day phlebotomy and bronchoscopy were performed. TREM-1 (12 patients) and TREM-2 levels (6 patients) on neutrophils and monocytes/macrophages in blood and BALF were assessed using flow-cytometry. VAP was diagnosed using the clinical pulmonary infection score

${ }^{1}$ Royal Marsden NHS Foundation Trust, Critical Care, London, United Kingdom

Full list of author information is available at the end of the article
(CPIS) and semi-quantitative microbiology and confirmed using HELICS criteria. In addition, peripheral blood white cell count and CRP levels were determined.

\section{Results}

mTREM-1 in BALF and its BALF/blood ratio rose in four out of the five patients each prior to VAP development (static in one out of five). BALF mTREM-1 and its BALF/ blood ratio rose in both patients with worsening VAP and fell in five out of six patients with resolving VAP (static in the other). White cell count and CRP levels did not correlate with VAP.

Neutrophilic TREM-1 changes in BALF broadly fitted two patterns: either mirroring changes with mTREM-1 but with a lower magnitude, or falling with infection development.

Considering TREM-2, BALF mTREM-2 either remained similar or rose prior to VAP development of VAP. The level rose with worsening VAP and fell with resolution, akin to the changes in mTREM-1. For nTREM-2, levels remained static prior to infection, but rose during VAP development and resolution.

\section{Conclusions}

BALF mTREM-1 and its BALF/blood ratio rise and fall with VAP development and resolution, highlighting the potential role of TREM- 1 in the pulmonary immune response and its role as a putative biomarker for VAP diagnosis. Monocyte and neutrophils differed in their changes in TREM-1 and TREM-2 receptor levels over time. TREM-1 and TREM-2 warrant further study in patients with pneumonia. 


\section{Grant acknowledgement}

This study was funded by the National Institute of Academic Anaesthesia and the Westminster Medical School Trust Fund

\section{Authors' details}

${ }^{1}$ Royal Marsden NHS Foundation Trust, Critical Care, London, United Kingdom. ${ }^{2}$ Chelsea and Westminster Hospital NHS Foundation Trust, Magill Department of Critical Care, Anaesthesia and Pain, London, United Kingdom. ${ }^{3}$ Imperial College London, Department of Surgery and Cancer, London, United Kingdom. ${ }^{4}$ Imperial College London, Immunology Section, Department of Medicine, London, United Kingdom. ${ }^{5}$ Imperial College Healthcare NHS Trust, Department of Immunology, London, United Kingdom. ${ }^{6}$ Chelsea and Westminster Hospital NHS Foundation Trust, Department of Respiratory Medicine, London, United Kingdom.

Published: 1 October 2015

\section{References}

1. Grover V, Pantelidis P, Soni N, Takata M, Shah PL, Wells AU, et al: A biomarker panel (Bioscore) incorporating monocytic surface and soluble TREM-1 has high discriminative value for ventilator-associated pneumonia: a prospective observational study. PloS One 2014, 9(10): e109686.

2. Sharif O, Gawish R, Warszawska JM, Martins R, Lakovits K, Hladik A, et al: The triggering receptor expressed on myeloid cells 2 inhibits complement component 1q effector mechanisms and exerts detrimental effects during pneumococcal pneumonia. PLoS Pathog 2014, 10(6):e1004167.

doi:10.1186/2197-425X-3-S1-A434

Cite this article as: Grover et al:: Temporal changes in monocytic and neutrophilic trem-1 and trem-2 surface receptors in blood and bronchoalveolar lavage fluid in the development and resolution of ventilatorassociated pneumonia (VAP). Intensive Care Medicine Experimental 2015

3(Suppl 1):A434

\section{Submit your manuscript to a SpringerOpen ${ }^{\odot}$ journal and benefit from:}

- Convenient online submission

- Rigorous peer review

- Immediate publication on acceptance

- Open access: articles freely available online

- High visibility within the field

- Retaining the copyright to your article 